\title{
Stage One of the Aristotelian Proof: A Critical Appraisal
}

\author{
Joseph C. Schmid ${ }^{1}$
}

Accepted: 4 March 2021

(c) The Author(s), under exclusive licence to Springer Nature B.V. 2021

\begin{abstract}
What explains change? Edward Feser argues in his 'Aristotelian proof' that the only adequate answer to these questions is ultimately in terms of an unchangeable, purely actual being. In this paper, I target the cogency of Feser's reasoning to such an answer. In particular, I present novel paths of criticism-both undercutting and rebutting-against one of Feser's central premises. I then argue that Feser's inference that the unactualized actualizer lacks any potentialities contains a number of non-sequiturs.
\end{abstract}

Keywords God $\cdot$ Aristotelian proof $\cdot$ Change $\cdot$ Per se chains

\section{Introduction}

Feser's Aristotelian proof is divided into two stages. Stage one seeks to demonstrate the existence of a purely actual, unactualized actualizer of the existence of actpotency composite beings, and the second stage identifies such a being with God.

For purposes of space, I will not quote Feser's (2017: 35-36) syllogized proof here. Here's a summary: Whatever reduces from potency to act (i.e. whatever potency is made actual or becomes actual) is causally actualized by something in a state of actuality. But any substance that is a composite of act and potency is, at any moment at which it exists, reducing from potentially existent to actually existent and hence requires a concurrent sustaining actualizer of its existence. This hierarchical or per se chain ${ }^{1}$ of sustaining actualizers cannot be infinite, and thus it must terminate in a purely actual, unactualized actualizer.

\footnotetext{
${ }^{1}$ Chains of causes/changes ordered per se are ones wherein the relevant causal power or property is wholly (concurrently) derivative in all secondary (non-first, non-fundamental) members of the chain. Such secondary members have the relevant causal power or property only derivatively and instrumentally; they do not possess it of themselves but merely transmit the causal power or property bestowed to them. To remove the primary member, then, is to simply collapse the causality of the chain.
}

Joseph C. Schmid

schmi215@purdue.edu

1 Purdue University, 610 Purdue Mall, West Lafayette, IN, USA 
Let us briefly consider the structure of my appraisal. I begin by discussing the dialectical context of Feser's Aristotelian proof. I then argue that a number of defeaters afflict premise seven of Feser's argument. Next, I articulate a new account of per se chains, arguing that it provides an undercutting defeater for the argument. Finally, I argue that Feser's (implicit) inference from 'presently unactualized actualizer' to 'purely actual actualizer' is a non-sequitur on multiple fronts.

\section{Dialectical Context}

Before turning to my appraisal of Feser's Aristotelian proof, I wish to get clear on the dialectical context thereof. We are in a context wherein Feser is aiming to give a positive demonstration of God's existence. As such, the burden is on Feser to provide those who do not already accept his premises with reasons or justification for accepting them.

As I use the phrases here, an undercutting defeater does not show a premise/ assumption to be false. Instead, it merely shows that it lacks proper justification. ${ }^{2}$ This contrasts with a rebutting defeater, which aims to show the actual or probable falsity of a premise/assumption.

There is one final thing to note concerning the dialectical context: the independence of the Aristotelian proof from a variety of other large-scale theoretical commitments. In particular, Feser aims for his Aristotelian proof to be independent of his Thomistic proof in which he relies on the Thomistic conception of esse, the real distinction between essence and esse, and so on. He also aims for it to be independent of other large-scale theoretical commitments like presentism or eternalism (2017: 50) and Aristotelian hylomorphism (2017: 28-29).

With these dialectical points covered, let us begin my appraisal by considering premise seven of Feser's argument.

\section{Premise Seven}

Let us first examine the justification for premise seven of Feser's argument. Premise seven states that the 'existence of $\mathrm{S}$ at any given moment itself presupposes the concurrent actualization of S's potential for existence' (2017: 35).

As I shall argue, this premise is not adequately justified. To see this, we must first examine Feser's proffered justification. Feser writes:

What keeps the water in existence at any particular moment? After all, given the chemistry of the water, the matter that makes it up also has the potential to

\footnotetext{
${ }^{2}$ Note that the relevant sense of justification here attaches to the one who doesn't already accept the argument/premise/assumption in question. The question is whether the argument-or, more accurately, its premises or what is said on their behalf-gives those who don't already accept the argument (i.e., who don't accept its premises or assumptions) sufficient reason or justification to change their mind and accept it.
} 
exist instead as distinct quantities of oxygen and hydrogen. But that is not the potential that is being actualized right now; instead, it is that matter's potential to exist as water that is being actualized right now. Why? It is no good to answer that such-and-such a process occurred at some time in the past so as to combine the hydrogen and oxygen in just the right way. That tells us how the water got here, but that is not what we are asking about... What we're asking about, again, is what keeps the water in existence at any instant at which it does in fact exist. (2017: 27)

There is much to unpack here. First, notice that Feser claims that it is the matter's potential to exist as water that is presently 'being actualized'. But 'being actualized' is arguably a notion of causal actualization. Instead of claiming the matter's potential is presently being actualized, then, a neutral description would say that the matter's potential to exist as water is presently actual.

But not all actualities consist in or involve reductions of potency to act. ${ }^{3}$ There are things that are (i) actual but (ii) whose actuality is not an actualized one-that is, not one consisting in the (concurrent) reduction of potency to act (by some causal actualizer). For Feser, one example of this would be God. God is actual, but his actuality does not consist in a reduction from potency to act. It is an unactualized actuality. For those who do not already accept Feser's premise- that is, those who do not already accept that substances are concurrently reducing from potency to act in respect of their actual (substantial) existence-one example of an actuality that is an unactualized actuality may very well be the present existence of the water. The point for now is that Feser has, in the passage thus cited, given those in this latter camp no reason to abandon their view, since he has simply described from the getgo that the water's actuality is an actualized actuality.

Now, notice that once we alter the phrasing to the neutral 'the matter's potential to exist as water is presently actual right now,' we cannot straightforwardly infer the need for a concurrent, sustaining efficient cause of the water's existence. Consider Feser's causal principle (CP) captured in premises four and five. Crucially, CP demands only an efficient causal actualizer when there is a reduction from potentiality to actuality - it does not claim that whatever is presently actual requires efficient causal actualization. The neutral description of the water situation, however, only allows us to conclude that the matter's potential is presently actual. And as to why this present actuality consists in a reduction of potency to act, no justification has been proffered.

Merely alleging that detractors of the Aristotelian proof have not addressed the question, 'what concurrently keeps the water in existence at any given moment?' will not do by way of response. For consider again the CP. According to CP, a concurrent causal 'keeper' or sustainer of the water's existence is demanded only if the water is, after all, (presently) reducing from potency to act in respect of its existence.

\footnotetext{
${ }^{3}$ Note that in saying that something causes a reduction of potency to act, I am intending to refer to efficient causal actualization of the potential for the existence of the whole substance here, since that is precisely the kind of reduction of potency to act that concerns Feser in his Aristotelian proof.
} 
And, of course, this is precisely the question at hand-the very point of contention in this dialectical context is whether the water is, after all, presently reducing from potentially existent to actually existent.

Here is a second response one might give. One may argue that, per the PSR, the present existence of the water (or any substance for that matter) requires an explanation. And absent a concurrently operative existential sustaining cause, there is no explanation for the present existence of the water. Call this response the 'PSR Response'.

The PSR Response, however, won't work. For, plausibly, past things can and do legitimately explain the existence of present things. ${ }^{4}$ Indeed, it seems difficult to square our ordinary, common sense explanatory practices (and, for that matter, our scientific practices) with a position on which past things lack explanatory force. Delving into arguments in favor of the legitimacy of past things' explaining present things, though, would take us too far afield given present purposes. Two notes suffice for now.

First, a dialectical point: Feser himself seems to agree that past things can (causally) explain present things. ${ }^{5}$ Second (and more importantly), a point concerning defeaters: even if one holds that past things cannot legitimately explain present things, what matters for present purposes is that neither Feser nor the (hypothetical) proponent of the PSR Response have-in the dialectical context at hand-given those who think the present existence of an act-potency composite object could be explained by the some past thing (say, the immediately temporally prior state and existence of the object in question) any reason to abandon their view. (Other explanations are available to the detractor of the Aristotelian proof, too-for instance, inertial persistence (cf. Schmid, 2021).) And in that case, the PSR Response and premise seven face an undercutting defeater, since they (i) require it to be false that the present existence of such an object could be so explained, but (ii) do not provide adequate reason to think such explanations false/inadequate.

As a third response, Feser might argue that we have clear experiential cases wherein more fundamental realities efficiently causally sustain less fundamental realities, and hence, we have grounds for holding that substances like water are presently reducing from potentially existent to actually existent. Indeed, Feser writes:

The potential of the coffee to exist here and now is actualized, in part, by the existence of the water, which in turn exists only because a certain potential of the atoms is being actualized, where these atoms themselves exist only because a certain potential of the subatomic particles is being actualized. (2017: 26-27)

However, this response is mistaken. Notice that the entities cited as alleged efficient sustaining actualizers are actually parts of the coffee: water is a constituent of

\footnotetext{
${ }^{4}$ What's more, we will see later that, plausibly, we need not even appeal to past states to explain present ones. I will provide (what I take to be) a plausible metaphysical account of per se chains on which the absence of a tendency to expire or annihilate, combined with a few other conditions, explains the present existence of the substance.

5 Feser (2019).
} 
coffee, atoms are constituents of water, the subatomic particles are constituents of the atoms, and so on. Why is one mistaken in identifying parts of substantial wholes as sustaining efficient causal actualizers of said wholes?

One reason derives from a plausible Aristotelian view of the relation between parts and the substantial wholes they compose. According to this view, the identity of a substance's parts makes sense only in light of the identity of the whole substance - that is, whole substances are in some sense prior to and more fundamental than their parts. So, for instance, something's being my kidney seems to presuppose the more fundamental reality of $m e$ as a substantial unity. Parts, then, presuppose the (ontologically) prior existence of their substance and thus cannot efficiently causally explain its existence.

Note that the above problem for the appeal to proper parts as efficient causes of their wholes is technically conditional in nature: if one finds certain Aristotelian or non-reductionist views of substances plausible, then one has pro tanto reason to reject the appeal to parts as efficient causes of their wholes.

Here are three further reasons for this conclusion. First, we have been given no reason why a relation of composition is also a relation of efficient causal actualization (indeed, we've seen reasons to reject this). Second, we've been given no reason why such causes count as efficient rather than material causes. Third, because the per se chain in question involves the more fundamental members composing less fundamental ones, the first member in such a series will simply be an uncomposed composer. But—given Feser's conception of God-God is not a component of anything.

A fourth response on Feser's behalf might run as follows. Wholes are merely in potency to the parts that compose them unless and until the parts are concurrently combined. Hence, whole substances—at any moment at which they exist—reduce from potency to act in respect of their existence.

This response, however, seems to beg the question at issue. For it is precisely the question at issue whether wholes are merely in potency unless and until their parts are concurrently held together. This amounts merely to presupposing that it is false that wholes are actual without reducing from potency to act in respect of their existence.

Nor will it do to suggest (as a fifth response) that the possibility that S's parts compose a different substance entails that $\mathrm{S}$ reduces from potentially existent to actually existent. From the fact that something could be otherwise than it in fact is, it does not follow that its current state is one involving a reduction from potency to act. $^{6}$

\footnotetext{
${ }^{6}$ All it tells us is that (i) $\mathrm{x}$ is actual, and (ii) $\mathrm{x}$ has the potential to be otherwise. But the conjunction of (i) and (ii) neither means nor entails that x's actuality consists in a present reduction of potentially existent to actually existent.
} 


\section{Per Se Chains}

In this section, I offer what I take to be another undercutting defeater of the Aristotelian proof. To accomplish this, I first articulate a new metaphysical account of per se chains ${ }^{7}$ of which each of the following seem true: (i) it is prima facie plausible; (ii) it is explanatorily powerful; (iii) if true, it would undermine the Aristotelian proof; and (iv) neither the Aristotelian proof nor what is said in justifying its premises gives those who hold to the account (or are neutral on it) reason to abandon their position.

The account runs as follows: A per se, sustaining cause $\mathrm{C}$ is required for substance S's being in condition or outcome $\mathrm{O}$ only if (i) there is some causal or explanatory factor or force $\mathrm{F}$-intrinsic or extrinsic to $\mathrm{S}^{8}$ - acting on $\mathrm{S}$ to bring $\mathrm{S}$ toward some condition or outcome $\sim \mathrm{O}$; (ii) $\mathrm{F}$ is a net factor or force in the absence of C's causal operation; and (iii) S (or some state of affairs involving $\mathrm{S}$ ) is in condition or outcome $\mathrm{O}$ distinct from $\sim \mathrm{O}$. I shall clarify the meanings of the various terms in the paragraphs that follow. For now, I simply note that the account is only specifying one necessary condition for per se chains. It does not purport to give a full analysis of such chains in terms of necessary and sufficient conditions. As we will see, however, the account nevertheless provides a foundation for a new undercutting defeater of the Aristotelian proof.

I want to begin with the account's prima facie plausibility. Consider one of Feser's examples of a per se causal chain: the cup's being held aloft. This can be represented as: cup-table-floor-foundations-Earth. Other uncontroversial examples of per se causal chains include a lamp being held aloft by chains, in turn being held aloft by the ceiling, and so on; the stone moved by the stick, in turn moved by the hand, and so on; and gear one being turned by gear two, gear two being turned by gear three, and so on.

Notice, though, that in each of these chains, it seems plausible that the principal reason concurrent causal sustenance is required is that, absent such sustenance, there is some 'net force' or 'net causal factor' that is causally contributing to a single, definite outcome. ${ }^{9}$ In other words, the causal operation of the sustaining, per se cause $\mathrm{C}$ seems required precisely because $\mathrm{C}$ acts against what would otherwise be a net causal factor towards some different outcome.

To see why this is at least plausible, consider again Feser's example. It seems that precisely because (absent the table's existence) the cup would revert to the ground that it requires causal sustenance to remain in the air, and this, in turn, is because there is a net causal factor (namely, gravity) operating on the cup that the table is

\footnotetext{
7 Or, at least, an account of one necessary condition for such chains.

${ }^{8}$ An intrinsic causal factor or force would be something like a natural tendency, inclination, or disposition inherent to a thing; an extrinsic one would be something like the effect of gravity, friction, etc.

9 I don't mean net force in an expressly mechanistic or physical way (although such forces are sub-categories of what I mean). Instead, I just mean a causal factor or group of causal factors whose overall causal contribution is like a vector quantity insofar as it contributes toward a definite end state or outcome and is not counterbalanced by some other causal factor(s).
} 
actively preventing from achieving its definite causal outcome (in this case, attraction toward the center of Earth's mass). ${ }^{10}$

At the very least, then, it seems prima facie plausible that a requirement of per se chains is that there is either (i) a causal force that inclines things toward outcome $\sim \mathrm{O}$ that is contrary to the outcome $\mathrm{O}$ produced by the causally sustaining intervention, or (ii) a natural tendency, inclination, or disposition of a thing toward $\sim \mathrm{O}$ that is actively being suppressed by the causal sustainer in order to maintain $\mathrm{O}$.

Let us now consider the account's explanatory power. Consider, first, that the account nicely explains each of the aforementioned uncontroversial cases of per se chains. For as we have seen, in each uncontroversial case of per se chains (the cup held on the table, the chains held aloft, the hand-stick-stone, the gears, etc.), the non-fundamental members (i.e., the ones being causally sustained by the primary or fundamental member) are invariably found to be under the influence of vector-like causal factors $\mathrm{V}$ that incline them toward a definite outcome $(\sim \mathrm{O})$ - and the primary, sustaining cause invariably counteracts $\mathrm{V}$ with a causal vector (with either equal or greater magnitude than $\mathrm{V}$ ) that is in the opposite 'direction' of $\mathrm{V}$ (i.e., toward $\mathrm{O}$ instead of $\sim$ O).

Second, the account nicely explains why the non-primary, less fundamental members require a sustaining cause. For it would simply be inexplicable if $S$ retained its condition or outcome $\mathrm{O}$ in the presence of net causal factors $\mathrm{V}$ inclining $\mathrm{S}$ toward $\sim \mathrm{O}$ and in the absence of some primary, sustaining cause that counteracts $\mathrm{V}$ to keep $\mathrm{S}$ in $\mathrm{O}$.

Third, the account also explains why per se chains plausibly cannot regress infinitely (in the sense of having infinitely many non-fundamental members without some fundamental sustaining cause of the series). For suppose the account is true; then, it is no surprise why infinite chains (subordinated per se) of non-fundamental members (without a primary, sustaining cause) are impossible. For then, there is a net causal factor or group of factors acting on the members of the chain without anything counter-acting such factors. Once again, it would then be inexplicable as to why or how the infinite chain's members retain condition, property, or outcome $\mathrm{O}$.

Fourth, the account can also explain the wholly derivative nature of per se chains (Cohoe, 2013: 839-840). For if the account is true, then the less fundamental members' being in condition $\mathrm{O}$ is due wholly to the sustaining cause that provides the counteracting (vector) causality. The less fundamental members wholly derive their being in condition $\mathrm{O}$ from the primary member which provides the counteracting causality; they are in $\mathrm{O}$ only insofar as the primary member continuously and concurrently provides the counteractive causality. And for each member $\mathrm{M}$ in the chain, M's being in $\mathrm{O}$ depends on all previous members insofar as the non-primary previous members 'channel' the vector causality to $\mathrm{M}$ from the primary cause $\mathrm{C}$.

\footnotetext{
10 The same seems, plausibly, to apply to the other examples of per se chains. For instance, the stone has net causal factors operating on it so as to keep it stationary (friction, gravitational and normal forces, and so on). A concurrent sustaining cause of the stone's motion plausibly seems required precisely because such a cause contravenes the causal activity of the friction, gravity, etc. toward the definite outcome of stationary spatial position.
} 
Fifth, it accounts very well for cases where, plausibly, no per se sustaining cause is needed. For instance, return to Feser's cup. Plausibly, absent any gravitational force pulling it down, it simply retains its spatial location without causal sustenance. Consider astronauts on the ISS who, upon placing a cup in location L, observe the cup remain in L without any causal factor sustaining it there. Plausibly, the only reason the cup would fail to remain three feet above ground (on Earth) is because there is a net causal force acting on it to pull it toward a given outcome. And the reason it is in fact able to remain three feet high even in the presence of (what would otherwise be) a net causal factor seems to be because some $\mathrm{C}$ is actively concurrently preventing the net factor from eliciting its characteristic outcome. ${ }^{11} \mathrm{C}$ accomplishes this by providing a causal force or factor towards an outcome contrary to that dominant in C's absence.

But absent a tendency or causally inclining factor toward either $\mathrm{O}$ or $\sim \mathrm{O}$, it seems plausible that $S$ will simply remain in the condition or state in which it is in, as there would be no reason or explanation as to why it deviated away from the outcome in which it actually finds itself. And this is precisely what the cup on the ISS seems to reveal: although the cup by itself has no capacity or causal inclination to be in any particular location, it will nevertheless remain in the actual location $\mathrm{L}$ in which it finds itself without requiring an external causal factor keeping it there. And again, this is plausibly because (i) the cup is presently in L; (ii) any deviation from L would be inexplicable in the absence of a tendency or causal factor inclining the cup away from L; and (iii) there is no such tendency or causally inclining factor operative.

\section{Undercutting Defeater}

With the plausibility and explanatory power of the account covered, we can now see why the account provides an undercutting defeater for the Aristotelian proof. Applying the account to a substance's actual existence, we get the following: a per se, sustaining cause $\mathrm{C}$ is required for S's actual existence only if (i) there is some $\mathrm{F}$ (either intrinsic or extrinsic to $\mathrm{S}$ ) acting on $\mathrm{S}$ to bring $\mathrm{S}$ toward non-existence; (ii) $\mathrm{F}$ is a net factor or force in the absence of C's existential sustenance; and (iii) S actually exists such that actual existence is distinct from the condition or outcome of $S$ 's non-existence.

But here's the rub: on the basis of the Aristotelian proof (its premises and that which Feser says on their behalf), conditions (i) and (ii) have simply not been adequately justified as holding. Because these are necessary conditions (per the account in question) for the requirement of a sustaining cause, it follows that, on the basis of the Aristotelian proof, the need for a per se, sustaining cause of S's actual existence (espoused in premise seven) has not been adequately justified. ${ }^{12}$

\footnotetext{
${ }^{11} \mathrm{C}$ would therefore be like a vector quantity that counterbalances in the opposite 'direction' of what would otherwise be a net causal factor/force.

12 This follows provided that we accept a kind of epistemic modus tollens (i.e., a kind of closure principle) - if we know that p entails q, and we know that we are inadequately justified in accepting $q$, then we know or are at least in a position to know that we are inadequately justified in accepting $\mathrm{p}$.
} 
To put the problem more concretely: under the account of per se chains I have provided, if substance $S$ lacks a tendency either way (neither towards persistent existence nor existential expiration/annihilation), then once placed in condition $\mathrm{O}$ (i.e., once brought into actual existence), $\mathrm{S}$ will simply remain in $\mathrm{O}$ as a form of stasis. Its continually occupying such an outcome or state will simply not involve a reduction of potency to act but will instead simply be a persisting state of stasis or actuality. And this follows upon the account in question: any deviation from the actual state, condition, or outcome $\mathrm{O}$ in which $\mathrm{S}$ finds itself would be inexplicable in the absence of (i) a tendency toward $\sim \mathrm{O}$ or (ii) a net causal factor inclining $\mathrm{S}$ toward $\sim \mathrm{O}$.

But Feser has given those who accept my account (or even those who are neutral on it) no reason to abandon their view-a view which, if true, would undermine the Aristotelian proof. The justifications Feser proffers on behalf of premise seven demonstrate neither (a) the falsity of my account nor (b) the existence of either (i) a tendency ${ }^{13}$ of things to expire or annihilate or (ii) a net causal factor 'pulling' or 'inclining' things toward non-existence at any moment at which they exist. And as we have seen, these are precisely what need to be ruled out in order to affirm premise seven.

Before turning to my next criticism of the Aristotelian proof, I wish to emphasize that I am not claiming that this account of per se chains is correct. Nor do I claim that those of Aristotelian-Thomist persuasion rationally ought to accept it, or that they wouldn't disagree with it. Instead, my sole purpose has been to show why someone (like myself) might be attracted to such an account of per se chains and how the justification proffered on behalf of the Aristotelian proof's premise seven does not provide me (or someone neutral on my account) with reason to abandon my position.

\section{Objection}

One might object to my account of per se chains as follows: While the account is plausible for many cases of per se chains, it seems to fail for other cases. Consider, for instance, the illumination of a surface (like the moon, or the surface of a wall on which a flashlight is shining). Some Thomists are fond of giving this as an instance of a per se causal chain. But it does not seem to involve a vector-like counteracting causal factor. ${ }^{14}$ What to make of this objection?

I have three responses. First, it is not clear that the case of illumination is a per se causal chain. Consider the moon's present illumination. The causal power or property of the series here is something like 'being illuminated'. What is the per se cause of this property? It cannot be the sun. For if you removed the sun, the moon would remain illuminated for about $8 \mathrm{~min}$. But the removal of a per se cause collapses the causality of the chain. (Nor will it be photons between the sun (or Earth) and moon.)

\footnotetext{
13 A 'tendency' does not only mean a probabilistic disposition-it could also mean an immediate reversion to another condition (or no condition at all, in the case of non-existence).

14 Thanks to an anonymous referee for this objection.
} 
The only candidate per se cause, then, would seem to be the collection of photons presently 'striking' or 'bouncing off' the moon's surface. But is not that the very thing that 'being illuminated' consists in? In other words, the 'effect' in this per se chain is ' $x$ 's being illuminated'. But ' $x$ 's being illuminated' seems to be nothing other than 'photons' striking/bouncing off $\mathrm{x}$ '. In that case, though, the effect just is what we previously took to be the only candidate cause (viz., the photons' striking/ bouncing off $\mathrm{x}$, where $\mathrm{x}$ is the moon). But surely that is absurd; a cause and effect must be distinct. Supposing this is a per se chain, then, seems to end in absurdity. Hence, plausibly, it is not a per se chain. ${ }^{15}$

Second, even if this is a per se chain, it is not clear why my account does not capture it. The vector-like causal or explanatory factors that maintain the non-illumination of the relevant surface could plausibly be (i) the nature of reflective surfaces and (ii) the absence of light in the surface's ambient environment. The former is an intrinsic explanatory factor, while the latter is an extrinsic explanatory factor. These can jointly comprise a kind of causal or explanatory vector directed towards the outcome or condition of non-illumination. A counteracting causal or explanatory vector would either alter the nature of the reflective surface (by, say, giving it some lightemitting property) or the extrinsic environment (by introducing light). ${ }^{16}$

Third, even if the case of illumination is a per se causal chain, and even if my account fails for it, the onus is on Feser (and proponents of the Aristotelian proof) to justify why existence is more like the case of illumination than the other cases that my account does capture. But, importantly, Feser has not justified this. Thus, we still seem to have an undercutting defeater on our hands.

\section{Existence as Stasis}

The difficulties for Feser's Aristotelian proof extend further. One difficulty in particular stems from one way Feser provides of reconciling $\mathrm{CP}$ with mechanical inertia. The account treats uniform spatial motion as stasis or unchangingness rather than involving change as the actualization of potential. Feser writes:

$[\mathrm{P}]$ recisely because the principle of inertia treats uniform local motion as a 'state,' it treats it thereby as the absence of change. ... In this case, the question of how the principle of motion [i.e. CP] and the principle of inertia relate to one another does not even arise... (2013: 239, 250-251)

But just as we can understand uniform spatial motion as stasis or unchangingness, it seems we can equally justifiably understand persistence in existence as an absence

\footnotetext{
15 The underlying problem seems to be that we only have a single event here: photons' presently bouncing off the moon. We don't have two distinct events (which is dissimilar to per se chains of causation, wherein there are distinct events (or, perhaps, objects) subordinated to one another as causes and effects). 16 Thus, if Feser wishes to locate existence within a per se chain, he must-in a principled, non-question-begging manner-point to some intrinsic or extrinsic fact about act-potency composites in virtue of which they require a counteracting vector in terms of per se causal sustenance. And this is something that-as I argued in the previous section—he has not (yet) done.
} 
of change. Indeed, remaining or persisting in existence is commonly thought not to involve change but rather the maintenance of a state of actuality. Indeed, we tend to think only that deviations from something's state of non-existence or existence count as changes (i.e., either coming into or passing out of being).

Even if we deny this common sense conception of persistence in existence as stasis, at the very least, it seems we lack any principled, non-arbitrary, non-questionbegging reason to think (i) persistence in uniform spatial motion is a state, but (ii) persistence in existence (at any moment) cannot be.

But if we lack justification for denying persistence in existence (at any moment) constitutes a state of unchangingness, then we lack justification for the application of CP (in the context of the Aristotelian proof) to S's persistence in existence at each moment. The demand for a per se sustaining cause of S's persistent existence at any moment on the basis of the causal principle is therefore unjustified. We have simply been given no reason to suppose S's existence-at-a-moment involves a process of actualization as opposed to a state of actuality.

I turn, next, to a final consideration against premise seven.

\section{A Tension}

Here is a rebutting defeater for Feser's Aristotelian proof: it seems incompatible with classical theism (i.e., the very thing he takes his argument to establish). For recall again premise seven: the existence of $S$ at any given moment itself presupposes the concurrent actualization of S's potential for existence. Here, Feser is explicit that any changeable substance $\mathrm{S}$ is such that its potential for existence is actualized at any moment at which $\mathrm{S}$ exists. In other words, changeable substances (at any moment at which they exist) reduce from potency to act in respect of their existence (cf. Feser, 2017: 63).

Indeed, the causal principle Feser employs (captured in premises four and five) requires that each changeable substance reduces from potency to act in respect of its very being or existence. For, again, the $\mathrm{CP}$ only allows us to infer a causal actualizer when there is a reduction from potency to act - it is completely silent about cases wherein there is not a reduction from potency to act. This is because CP only states that whatever reduces from potency to act is actualized by something in a state of actuality.

But under classical theism, creation cannot be the causing of something to reduce from potency to act. Creation does not consist in making substances go from potency to act. For ontologically prior to God's creative act, the only thing in existence (under classical theism) is God. Moreover, God is purely actual. Hence, no potencies exist prior to creation. And if no potencies exist prior to creation, then they only exist posterior to creation. But then each changeable substance's actuality is not (ontologically) preceded by potency. And if each changeable substance's actuality is not so preceded, then it is simply false that each changeable substance's actual existence consists in a reduction from potency to act. Plausibly, S's reducing from potency to act presupposes some potency requiring actualization by some causal actualizer. (Consider: plausibly, one cannot go from A to B if there is no such 
thing as A. (Can you go from Narnia to New York?) There must, then, be such a potency in order for $\mathrm{S}$ to go from potency to act.)

Feser may respond to the argument by distinguishing between passive and active potency, arguing that although passive potency does not pre-exist creation, active potency (in the form of God's active causal power or capacity) does. But, first, active potencies are not potentialities but instead a kind of actuality (Feser, 2014: 43). Second, Feser simply cannot be referring to God's active potency in premise seven. This is because the potency referenced in premise seven is one that is actualized, i.e., one that is caused. It is reduced from potency to act. But nothing in God is caused or actualized or reduced from potency to act.

Before moving on, I wish to emphasize that I do not claim that this is a problem for classical theism as such. Instead, my aim is to pinpoint a tension between classical theism and the Aristotelian proof's treatment of creation as the actualization of a potential.

Let us turn next to Feser's inference to the presently unactualized actualizer's being purely actual.

\section{Purely Actual}

Suppose we grant Feser that there are at least some concrete objects that reduce from potentially existent to actually existent at each non-first moment $\mathrm{m}$ of their existence. On the basis of $\mathrm{CP}$, Feser holds that such concrete objects require efficient causal sustenance for their actual existence at m. And any such chain, Feser argues, must have a first member. According to Feser, however, we can infer not only that such chains have a first member, but also that the first member is purely actual or unchangeable. I will argue, however, that this inference is a non-sequitur.

To show this, it is first necessary to quote at length Feser's justification for it. Feser writes:

[W]hat it means for such a series to have a first member is that there is something which can impart causal power to the other members of the series without having to have [emphasis added] that power imparted to it-something that has its causal power in a 'built-in' or nonderivative way. Now since what is being explained in this case is the actualization of a thing's potential for existence, the sort of 'first' cause we are talking about is one which can actualize the potential for other things to exist without having to have its own existence actualized by anything.

What this entails is that this cause doesn't have any potential for existence that needs to be actualized in the first place. It just is actual, always and already actual, as it were. Indeed, you might say that it doesn't merely have actuality, the way the things it actualizes do, but that it just is pure actuality itself. (2017: 27)

But notice that all we are entitled to conclude about the terminating actualizer A in a chain of per se actualization of substance S's existence at $\mathrm{m}$ is that (i) at $\mathrm{m}, \mathrm{A}$ is 
actual, (ii) at m, A is not reducing from potentially existent to actually existent, and (iii) at $\mathrm{m}$, A does not have to have its own existence actualized by anything. Indeed, Feser recognizes that this is all we are entitled to conclude about A, as Feser is careful to articulate the phrase 'having to have'.

Crucially, though, (i), (ii), and (iii) above are perfectly compatible with the possibility at $\mathrm{m}$ of A's having its own existence actualized by something else. All Feser has shown is that it is not necessarily the case that, at $\mathrm{m}$, A derives its existence from another. But that is perfectly compatible with the conjunction of A not in fact deriving existence from another and its being possible for A to derive existence from another. In such a case, however, A would still have a potential pertaining to its existence-namely, a potential (which is not actual) for its existence to be (or to have been) actualized - that is not right now reducing from potency to act or being actualized by another.

Because this point is central to the Aristotelian proof, it is worth dwelling on it further. All we are entitled to infer thus far is that (i) if there is a substance that is right now ${ }^{17}$ reducing from potentially existent to actually existent, then it requires a concurrent cause, and that (ii) if this concurrent cause is itself right now reducing from potentially existent to actually existent, then it requires a concurrent cause, and that (iii) since this constitutes a per se chain, the series cannot be infinite and hence terminates in a first member, A. For all Feser has shown, however, A is unalike the other members of the series only insofar as A is not right now reducing from potentially existent to actually existent. But this neither means nor entails that A cannot reduce from potentially existent to actually existent right now. All it entails is that A is not in fact presently reducing from potentially existent to actually existent.

We therefore cannot (on the basis of Feser's Aristotelian proof) infer A's being purely actual with respect to A's present existence, since all we are entitled to conclude is that A is presently actual with respect to its existence and not presently reducing from potentially existent to actually existent. If we want to establish that A is purely actual with respect to its present existence, we would not only have to show that A's present existence is actual without reducing from potency to act; we would also have to establish that A's present existence is such that it cannot possibly be presently reducing from potency to act. Feser has simply not established this.

But suppose Feser could establish that A is purely actual with respect to its present existence. Even so, it still would not follow that A is purely actual with respect to its existence simpliciter. This is because we are considering a chain of per se causes solely in the present moment. The causal role A plays concerning the presentmoment-indexed causal chain to which A stands as terminus is only a present causal role. Nothing seems to be entailed about A's existence in the past or the future; the causal role of A-qua indexed solely to the present moment-only seems to facilitate inferences about A's actuality with respect to the present. The present existence of the chain is (for all Feser has shown) the only explanatory lacuna A needs to fill. The effect is (according to the argument) wholly present, and hence, the only truths

\footnotetext{
17 Assuming, of course, that $\mathrm{m}$ is the present moment. This is in keeping with how Feser presents his argument.
} 
about A we seem able to infer are ones concerning its present existence and causal role. (Consider: A could go out of existence later (while the effect remains) since some other $\mathrm{A}^{*}$ could replace A.) We therefore seem entitled to infer only that A is purely actual with respect to its present existence-nothing follows about A's being purely actual with respect to its existence simpliciter. So, even granting Feser that A is purely actual with respect to its present existence, it does not follow that A is purely actual with respect to its existence simpliciter.

This problem is compounded further. For even if Feser could establish that A is purely actual with respect to its existence simpliciter, it does not follow that A is purely actual simpliciter. This is because there are potencies that do not relate to the very existence of the substance to which they belong. All we can infer from A's having an existence in a purely actual manner is that A has no potential to begin to exist, cease to exist, or fail to exist-in other words, A is a necessarily existent being. But necessary beings need not be unchangeable, since there are changes that are unrelated to the very existence of the substantial whole (viz., accidental as opposed to substantial changes). (E.g., while the neo-classical theistic $\operatorname{God}^{18}$ is a metaphysically necessary being, he can nevertheless change in respects wholly unrelated to his very (substantial) existence (i.e., unrelated to the beginning, end, or cessation of his substantial existence).)

There are, then, at least three non-sequiturs at play. First, it does not follow from A's being a presently unactualized actualizer that A is purely actual with respect to A's present existence; second, it doesn't follow from A's being purely actual with respect to A's present existence that A is purely actual with respect to existence simpliciter; third, it does not follow from A's being purely actual with respect to existence simpliciter that A is purely actual simpliciter. Putting these three together, A's being a presently unactualized actualizer (which is all Feser has (purportedly) established) does not entail A's utterly lacking in all potentialities, since any being which is a presently unactualized actualizer may_-for all Feser has shown-have potentials which simply are not right now being actualized or are not required to be actualized for A to serve as the terminus for a given per se chain of causes or changes.

\section{Changeable Necessary Beings}

The point about neo-classical theism points to a further difficulty afflicting Feser's argument. In particular, Feser's argument presupposes the metaphysical impossibility of changeable necessary beings. For suppose changeable necessary beings are possible; then, it is false that any act-potency composite being reduces from potentially existent to actually existent at any moment at which it exists. This is because (i) changeable necessary beings are act-potency composite beings, but (ii) changeable necessary beings cannot reduce from potentially existent to actually existent.

\footnotetext{
18 For articulations of the different models of God, especially what I've called 'neo-classical theism', see Timpe (2013), Mullins (2016), and Mullins (2020).
} 
For what it means to be a necessary being (as I use it) is to be a being that is necessarily actually existent. And what is necessarily actually existent cannot reduce from potentially existent to actually existent precisely because it is metaphysically impossible for any such being to be potentially existent in the first place.

The success of Feser's argument, therefore, presupposes the impossibility of changeable necessary beings. But no justification has been given for such a presupposition. Because it rests on an inadequately justified assumption, it follows that Feser's argument faces another undercutting defeater. At the very least, Feser has not given those who accept (or are even neutral on) the possibility of changeable necessary beings to abandon their view. (Indeed, if it seems plausible to one that there genuinely could be changeable necessary beings (as it seems to my mind), then one has positive reason against Feser's Aristotelian proof.)

\section{Response}

Now, Feser anticipates some of the non-sequitur worries I have been spelling out and attempts to circumvent them. His consideration of the non-sequitur objection(s) and his response are worth quoting at length:

For why not suppose instead that it has potentialities which are simply not in fact being actualized, at least not insofar as it is functioning as the first actualizer in some hierarchical series of causes? Perhaps those potentialities are actualized at some other time, when it is not so functioning; or perhaps they never are.

To see what is wrong with this objection, recall once again that ... the regress of actualizers that we are ultimately concerned with is a regress of the actualizers of the existence of things. The first actualizer in the series is 'first', then, in the sense that it can actualize the existence of other things without its own existence having to be actualized. So, suppose this first actualizer had some potentiality that had to be actualized in order for it to exist. What actualizes that potential? Should we suppose that it is something other than the first actualizer that actualizes it? But in that case, the so-called first actualizer isn't really the first actualizer after all... (2017: 66)

Feser's response, however, is misguided. For the objection at hand is not that the first actualizer A possesses some potentiality that has to be actualized in order for it to exist. The objection is threefold. First, even if A is presently unactualized in respect of its existence, it does not follow that $\mathrm{A}$ is purely actual with respect to its present existence; second, even if it did follow, it would not follow that A is purely actual with respect to existence simpliciter; and third, even if that followed, it would not follow that A is purely actual simpliciter. Nothing in Feser's response addresses any of these criticisms. Instead, Feser aims his reductio at the thesis that 'A has some potency that has to be actualized as a necessary condition for A to exist.' Feser is right that, given $\mathrm{CP}$, this claim entails that A cannot be the first, unactualized member of the chain. But this is not the criticism. 
The criticism is not that $\mathrm{A}$ has potencies for existence whose actualization are necessary conditions for its actual existence. It is instead that-for all Feser has shown-although $\mathrm{A}$ is not in fact presently reducing from potentially existent to actually existent, it could nevertheless be possible that A so reduces. ${ }^{19}$ Additionally, there may - for all Feser has shown-be potencies in A wholly unrelated to its presently actual existence. And this is something that Feser's reductio simply ignores. Feser has, in essence, performed a reductio on a claim irrelevant to the criticism at hand.

\section{Conclusion}

I have uncovered a number of new difficulties afflicting the Aristotelian proof. First, premise seven succumbs to a variety of undercutting and rebutting defeaters. Second, the inference to A's being purely actual is riddled with non-sequiturs. Although I have been quite critical of the argument, it is my hope that this article spawns greater dialogue and unity between defenders and detractors of the argument.

Acknowledgments I am thankful to two anonymous referees for helpful comments.

\section{References}

Cohoe, C. (2013). There must be a first: Why Thomas Aquinas rejects infinite, essentially ordered, causal series. British Journal for the History of Philosophy, 21(5), 838-856.

Feser, E. (2013). Motion in Aristotle, Newton, and Einstein. In E. Feser (Ed.), Aristotle on Method and Metaphysics. Palgrave Macmillan.

Feser, E. (2014). Scholastic metaphysics: A contemporary introduction. Editiones Scholasticae.

Feser, E. (2017). Five proofs of the existence of God. Ignatius Press.

Feser, E. (2019). Vallicella on existence-entailing relations and presentism. Blogspot. http://edwardfeser. blogspot.com/2019/04/vallicella-on-existence-entailing.html. Accessed 21 Feb 2020.

Mullins, R. T. (2016). The difficulty of demarcating panentheism. Sophia, 55, 325-346.

Mullins, R. T. (2020). God and emotion. Cambridge University Press.

Schmid, J. C. (2021). Existential inertia and the Aristotelian proof. International Journal for Philosophy of Religion. https://doi.org/10.1007/s11153-020-09773-9.

Timpe, K. (2013). Introduction to neo-classical theism. In J. Diller \& A. Kasher (Eds.), Models of God and Alternative Ultimate Realities (pp. 197-206). Springer.

Publisher's Note Springer Nature remains neutral with regard to jurisdictional claims in published maps and institutional affiliations.

19 More precisely, this is one prong of the three-pronged criticism of Feser's inference. 